\title{
The Novel WHO 2010 Classification for Gastrointestinal Neuroendocrine Tumours Correlates Well with the Metastatic Potential of Rectal Neuroendocrine Tumours
}

\author{
Juha Jernman ${ }^{a}$ Matti J. Välimäki ${ }^{b}$ Johanna Louhimoc Caj Haglund ${ }^{a, c}$ \\ Johanna Arola ${ }^{a}$ \\ a Department of Pathology, Haartman Institute and HUSLAB, ${ }^{b}$ Division of Endocrinology, Department of Medicine, \\ and ${ }^{\mathrm{C}}$ Department of Surgery, Helsinki University Central Hospital, Helsinki, Finland
}

\author{
Key Words \\ Carcinoid · Neuroendocrine tumour • Rectum • \\ Classification $\cdot$ Metastasis
}

\begin{abstract}
Background: Approximately $10-15 \%$ of gastroenteropancreatic neuroendocrine tumours (NETs, carcinoids) occur in the rectum, some of which are potentially able to metastasize. The new WHO 2010 classification of NETs applies to all gastroenteropancreatic NETs, but no reports have studied its correlation with the prognosis of rectal NETs. Patients and Methods: We retrospectively classified 73 rectal NETs according to the novel WHO 2010 and the previous WHO 2000 classifications. The aim was to assess the validity of the classifications in distinguishing indolent rectal NETs from metastasising tumours. Results: Using the WHO 2010 criteria, we identified 61 G1 tumours, none of which had metastasised during follow-up. Of $11 \mathrm{G} 2$ tumours, 9 had shown distant metastases. The only G3 neuroendocrine carcinoma that occurred had been disseminated at initial presentation. Conclusion: Our results show that rectal NETs classified as G1 according to the WHO 2010 classification have an indolent
\end{abstract}

clinical course, whereas G2 NETs often metastasise. The WHO 2010 classification of NETs predicts the metastatic potential of rectal NETs better than the WHO 2000 classification.

Copyright $\odot 2011$ S. Karger AG, Basel

\section{Introduction}

Neuroendocrine cells of endodermal origin are scattered throughout the gastrointestinal (GI) tract. These cells secrete peptide hormones and biogenic amines upon stimulation by the autonomic nervous system and thus regulate the functioning of the GI tract $[1,2]$. The peptide hormones and biogenic amines are stored in neurosecretory granules containing proteins such as chromogranin A. Neoplasms that arise from these cells used to be called carcinoid tumours; the appropriate modern term is neuroendocrine neoplasm, neuroendocrine tumour (NET) or neuroendocrine carcinoma (NEC). Most NETs express synaptophysin (a synaptic vesicle glycoprotein present in

C. Haglund and J. Arola contributed equally to this paper.

\section{KARGER}

Fax +4161306 1234

E-Mail karger@karger.ch

www.karger.com
(C) 2011 S. Karger AG, Basel

$0028-3835 / 12 / 0954-0317 \$ 38.00 / 0$

Accessible online at:

www.karger.com/nen
Juha Jernman

Department of Pathology, Haartman Institute

University of Helsinki, Haarmaninkatu 3, PO Box 21

FI-00014 Helsinki (Finland)

Tel. +358 331175 755, E-Mail juha.jernman@pshp.fi 
Table 1. Criteria for the classification of neuroendocrine tumours of the rectum

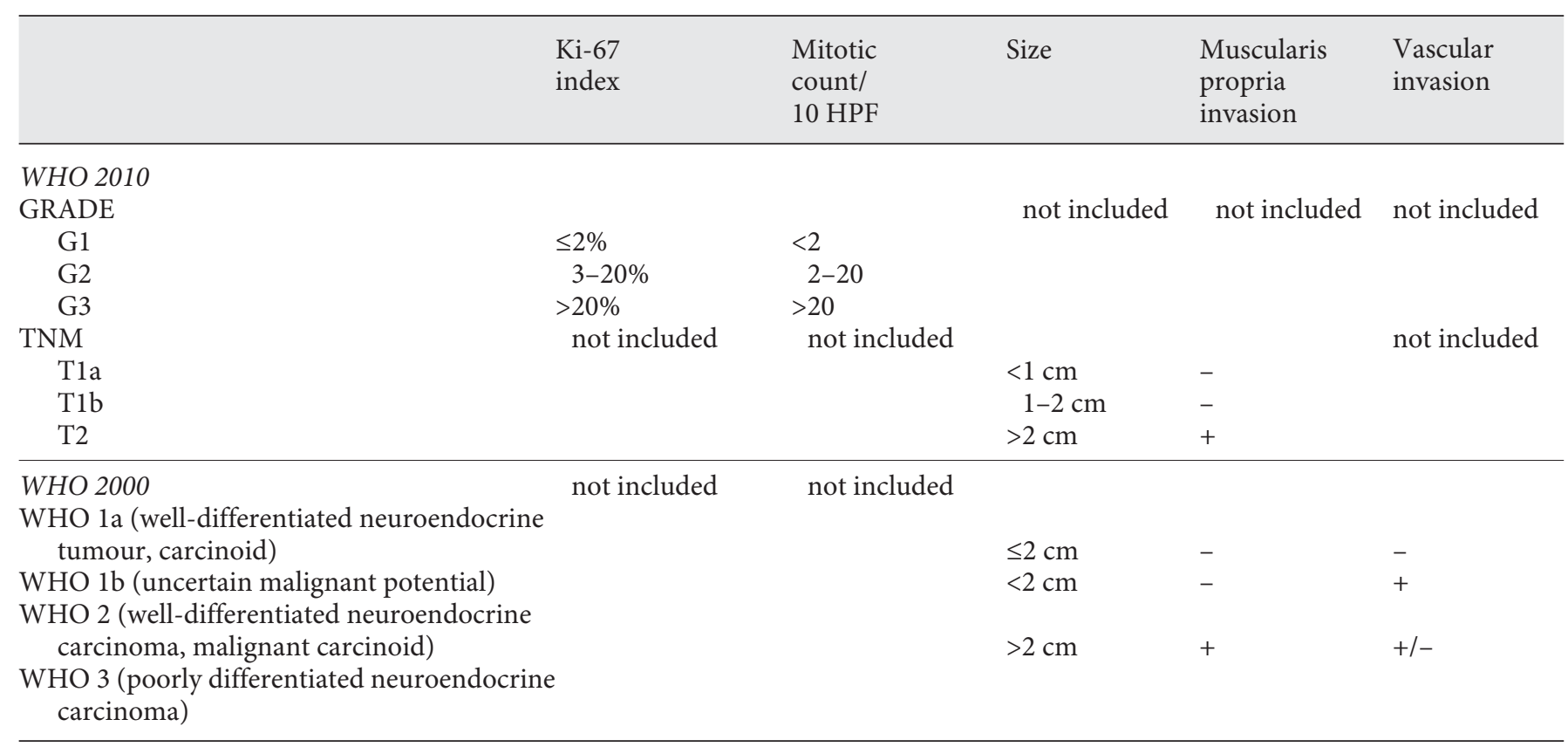

In the WHO 2010, the higher grade is assumed if Ki-67 index and mitotic count differ; in the WHO 2010 TNM, the tumour is classified as T2 if it is larger than $2 \mathrm{~cm}$ in diameter or if it invades the muscularis propria. T3 and T4 tumours are locally aggressive tumours (data not shown in the table). In the WHO 2000, the tumour is considered malignant (WHO 2), if it fulfils any of the criteria shown. HPF = High power fields.

neuroendocrine cells) and chromogranin A by immunohistochemistry [3-5]. Some tumours secrete peptide hormones or biogenic amines and are thus biologically active.

Rectal tumours represent $27.4 \%$ of the GI NETs [6] and have an age-adjusted annual incidence of 0.83 per 100,000 in the US [7]. Rectal NETs are usually small and are often discovered by chance during endoscopy. Patients with local disease have a favourable prognosis with a 5 -year survival rate of $88-91 \%$ [6-8]. The incidence of rectal NETs has increased in recent years [9], which is possibly due in part to increased awareness of this tumour entity among clinicians and pathologists, and partly to improved availability of endoscopy. However, a true increase in incidence cannot be excluded.

After the year 2000, NETs of the GI tract and the pancreas were classified according to the World Health Organization (WHO) criteria into 3 groups [10]. The criteria are detailed in table 1 . Hormonal activity was also taken into account in the WHO 2000 classification, but the proliferation index (Ki-67) was not included. Still, Ki-67 was considered a prognostic factor; tumours with a Ki-67 index of $\leq 2 \%$ were considered benign and those with a Ki67 index of $>2 \%$ malignant [11]. Previous reports indicate that rectal NETs are rarely positive for Cdx2 [12, 13]. Some $80 \%$ of rectal NETs express pancreatic polypeptide (PP), and $30 \%$ are positive for serotonin [14].

In the novel WHO 2010 classification for GI NETs, all tumours are considered malignant with the potential to metastasize. Tumour grade is based on proliferation (i.e. the Ki-67 index) and the mitotic count (table 1).The classification also includes a staging system. Well-differentiated tumours are called G1 or G2 NET, and the most malignant tumours, which in WHO 2000 were classified as poorly differentiated NECs, are now called large cell or small cell type G3 NECs. G3 carcinomas, highly aggressive neoplasms with poor prognosis [15], are rare in the rectum, but more common in the colon. Available evidence supports the new grading system for NETs of the stomach, duodenum and pancreas, but its prognostic value is less well documented in tumours of the intestine [16].

The purpose of our study was to evaluate the prognostic value of the WHO 2010 classification in predicting the metastatic potential of a rectal NET. Patients with distant metastases have significantly worse prognoses than do patients with local disease (without regional or distant 
metastases). According to the SEER (Surveillance, Epidemiology and End Results) database, 9\% of the patients with a rectal NET have disseminated disease $[7,17]$. Tumour size, elevated mitotic rate, invasive growth pattern, and lymphovascular invasion have been associated with worse prognoses but no reports have described how different classifications correlate with the prognosis of rectal NETs. In this work we used the novel WHO 2010 classification to retrospectively reclassify 73 rectal NETs and validated its prognostic value in terms of metastatic potential and patient survival. To the best of our knowledge, no other reports have assessed the prognostic significance of the novel WHO 2010 classification.

\section{Patients and Methods}

The Ethics Committee of the Helsinki University Central Hospital and the National Authority for Medicolegal Affairs approved the research setting.

\section{Patients}

For the period from 1980 through 2005, 118 rectal NETs are listed in the Finnish Cancer Registry. From our pathology laboratory database (QPati), we identified 73 viable cases for reanalysis. In 68 cases, we obtained the follow-up data from patient records. The 5 missing patients had been alive at the end of the follow-up period, but no clinical data had been available. The 45 tumours that were unavailable for this study were originally sent to private laboratories, so no archive tissue material could be obtained. Overtly malignant, metastasised cases had been treated in community hospitals and were thus included in the material. Recorded clinical data of particular interest included pre-treatment symptoms, surgical or endoscopic removal method, lymph node and distant metastases, and local recurrences. Symptoms, when the information was available, were categorised as follows: bleeding from the GI tract, other GI symptoms, and non-GI symptoms. Date and cause of death were obtained from the Finnish Population Registry and Statistics Finland. The last check-up date was in March 2011.

Only 3 patients had undergone bowel resection, 1 of whom had had the colon resected due to chronic colitis irresponsive to conservative treatment. A polypoid G1 NET in the rectum had been an incidental finding, lymph node status was unavailable and no evidence exists of metastatic lesions thus far. Another patient with a 40-mm G2 tumour had undergone bowel resection with lymph node metastases (2/4). This patient had developed liver metastases 12 years later. The third patient to undergo bowel resection had had a $30-\mathrm{mm}$ tumour with (simultaneous) liver and regional lymph node metastases. A total of 10 patients had been treated with mucosal resection, 12 with polypectomy, and for the rest of the patients $(n=49)$, the tumour had been removed in pieces, which sometimes makes invasion of the muscularis propria impossible to exclude; thus the T-status cannot be considered reliable in all cases. Lymph node status was available in only 2 patients, and very few patients had been investigated radiologically to exclude metastasis at the time of diagnosis, since the poten- tially malignant nature of these tumours had not always been recognised. Due to these facts, TNM-status cannot be considered reliable in this retrospective material.

Clinical Follow-Up

Follow-up data, which included mainly physical examination and repeated endoscopies, were available for 68 patients. The patients had been treated in different hospitals, and no standard scheme was used for follow-up. Most patients had undergone annual endoscopy, and follow-up had usually been terminated after 5 years or less. At the time of diagnosis, very few patients underwent imaging procedures to exclude metastases.

\section{Histology and Immunohistochemistry}

Tissue specimens were obtained from the pathology tissue archives of the Helsinki University Central Hospital and its affiliated hospitals in Uusimaa province in southern Finland. Two pathologists (J.J. and J.A.) reanalysed all tumours from hematoxylin-eosin (HE) stainings. The following parameters were registered: tumour size and invasion of the muscularis propria or vascular structures. The predominant growth pattern (i.e. trabecular, glandular, insular, or solid) was also registered for these tumours. Immunohistochemical positivity (at least $20 \%$ of the tumour cells) for chromogranin A confirmed the neuroendocrine nature of all tumours. Staining was carried out with polyclonal rabbit antichromogranin-A (A0430, 1:2000; DAKO, Glostrup, Denmark). Angioinvasion was confirmed or excluded from immunostaining with monoclonal mouse anti-CD31 (JC70, 1:100; DAKO). The expression of $\mathrm{Cdx} 2$, serotonin and $\mathrm{PP}$ was defined by immunohistochemistry [Cdx2, clone $\mathrm{Cdx} 2-88,1: 50$ (BioGenex, San Ramon, Calif., USA) serotonin, 5HT-H209, 1:10 (DAKO) and PP, polyclonal, 1:100 (Nordic BioSite, Stockholm, Sweden)]. The proliferation indices of the tumours were assessed in 2,000 neoplastic cells stained with monoclonal anti-Ki-67 (MIB-1, 1:75; DAKO). The tumours were then classified according to the WHO 2010 and WHO 2000 classifications (table 1).

\section{Statistics}

Correlations between various clinicopathological characteristics were assessed with $\chi^{2}$ and Fisher's exact tests. The KaplanMeier life-tables were calculated, and the significance of the difference in survival between subgroups was assessed with the logrank test. The Cox proportional hazards regression model was applied as a multivariate survival analysis. Since rectal NETs are quite rare, we evaluated both disease-free survival (occurrence of metastatic lesions, not local recurrence) and disease-specific survival (death of disease) as the end point in survival analysis. Because only one G3 tumour was entered in our material, it was excluded from statistical analyses. The analyses were performed with SPSS 17.0 software.

\section{Results}

During follow-up, 21 patients died, but only 6 of them died from metastatic NET. The mean age range of the 73 patients (28 males and 45 females) at the time of diagnosis was 53.8 years (23.5-93.7). The mean follow-up was 
Fig. 1. Histology and immunohistochemistry of rectal NETs: a NET G1, a HE, b chromogranin A, and c Mib-1 stainings. A NET G2, d HE, e chromogranin A, and f Mib-1 stainings. Both tumours are immunoreactive for chromogranin A (b, e). The NET G1 has a proliferation index of $1 \%$ (c), whereas MIB-1 staining is positive in up to $5 \%$ of the tumour cells in the NET G2 (f).
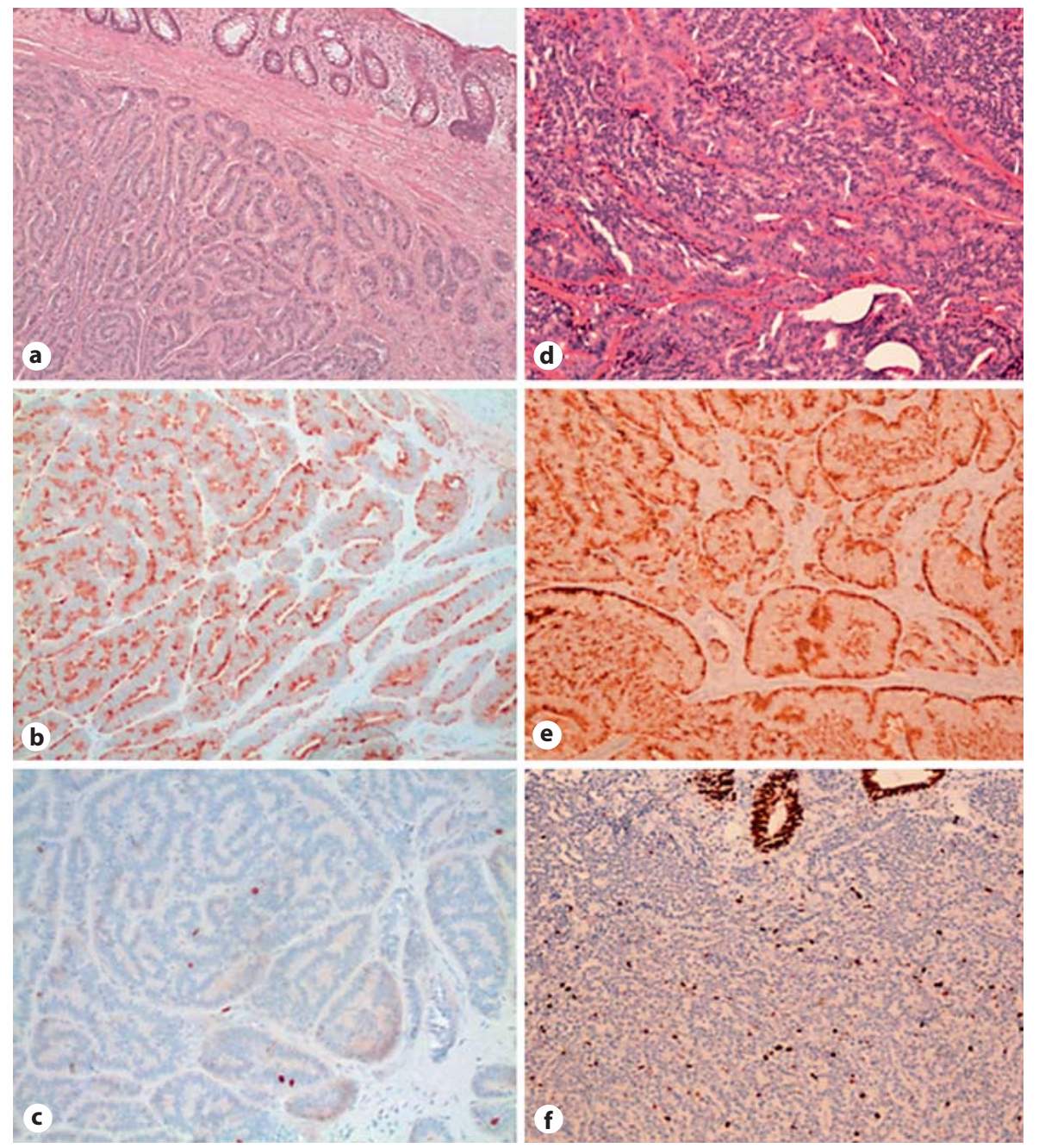

124 months (23 days to 314 months). The material included only one G3 NEC. This tumour showed a solid growth pattern and a Ki-67 index of 25\%. Due to small biopsies obtained from the tumour, the diameter could not be assessed from the histological specimen. Liver metastases were present at the time of diagnosis. The patient had died 22 months after diagnosis.

\section{Classification according to the WHO 2010 Criteria}

In this classification, tumour grade is based on the proliferation index and mitotic count. The mitotic count was very low in all tumours, including the metastasising ones. The highest count was $7 / 50$ high power fields, which is too low to qualify for G2. The grading was therefore based on the Ki-67 index.

Our material comprised 61 G1 tumours (fig. 1, table 2), none of which were metastatic, but 3 patients had under- gone endoscopic excision of a local recurrence 4-15 months after the primary diagnosis. The mean size of the G1 tumours was $3.6 \mathrm{~mm}$ (range $0.5-9$, median $3 \mathrm{~mm}$ ); 26 (43\%) of the patients were males and 35 (57\%) females. The material also included 11 G2 tumours (fig. 1), the mean size of which was $19 \mathrm{~mm}$ (range 4-40, median 17 $\mathrm{mm}) ; 2(18 \%)$ of the patients were males and $9(82 \%)$ females. Nine (82\%) patients had initially had or had developed metastatic disease. In 3 cases, the primary tumour and the metastatic lesions had been detected simultaneously. Late metastases had occurred in 6 patients, in whom the average elapsed time from detection of the primary tumour to distant metastasis was 60 months (range 4-151). Metastases had been detected in the liver (8 patients), lymph nodes of the lung hilus and mesenterium (2 patients), and bones (1 patient). Of the 11 G2 patients, 5 died of metastatic disease 1-66 months (average 28 
months) after surgery. Four patients with metastatic disease were alive with disease 38-163 months after primary diagnosis. The only patient with a G3 tumour had had metastatic lesions at initial presentation.

Two tumours expressed $\mathrm{Cdx} 2$ by immunohistochemistry: one was a $20-\mathrm{mm}$, metastatic G2 tumour, and the other a $10-\mathrm{mm} \mathrm{G} 2$ tumour that had thus far not metastasised. Both Cdx2-positive tumours expressed serotonin and the smaller one expressed PP as well. Five tumours expressed serotonin, 2 of which were G2 tumours (20 and $10 \mathrm{~mm}$ ) with a Ki-67 index of 5\%, the larger one having metastasized, and 3 others were smaller, non-metastatic G1 tumours (1.5, 3 and $7 \mathrm{~mm}$ ) with a Ki-67 index of $1 \%$. Expression of PP was detected in 25 tumours, 1 of which was metastatic. Hormonally positive tumours were exclusively positive for either serotonin or PP except for 1 tumour, which was positive for both.

\section{Classification according to the WHO 2000 Classification}

Of the 73 tumours, 65 were considered benign (WHO Ia) according to the WHO 2000 criteria. Metastases had later been found in 2 patients, and in 63 patients the disease had remained local during follow-up. Two tumours had been classified as having uncertain malignant potential (WHO Ib) at initial presentation. These tumours were less than $2 \mathrm{~cm}$ in diameter, but had vascular invasion and later showed metastasis. There were 5 tumours in the malignant group (WHO II), 4 of which had metastasised later; 1 tumour had remained local. The only poorly differentiated NEC (WHO III) had shown liver metastases at initial presentation.

\section{Statistical Analysis}

Assessed with $\chi^{2}$ and Fisher's exact tests, the WHO 2010 and WHO 2000 classifications, tumour size, vascular invasion, and muscularis propria invasion were found to correlate with the occurrence of distant metastases (table 2). The expression of $\mathrm{Cdx} 2$, serotonin or PP failed to correlate with metastatic potential; neither did gender, age, growth pattern, or symptoms (data not shown).

With the Kaplan-Meier life-tables and the log-rank test, the WHO 2010 classification was found to have prognostic power in relation to both metastatic potential and patient survival (fig. 2,3). When the occurrence of distant metastasis was selected as the end point, tumour size, vascular invasion and muscularis propria invasion were also found to correlate with the outcome, although the WHO 2010 classification proved to have the most signif-
Table 2. Correlation between clinicopathological characteristics and the occurrence of distant metastasis in rectal NETs assessed with the $\chi^{2}$ and Fisher's exact tests

\begin{tabular}{|c|c|c|c|c|}
\hline Variable & $\begin{array}{l}\text { No } \\
\text { metastasis }\end{array}$ & Metastasis & $\begin{array}{l}\text { Total } \\
\mathrm{n}\end{array}$ & $\begin{array}{l}\mathrm{p} \\
\text { value }\end{array}$ \\
\hline \multicolumn{5}{|l|}{ WHO 2010} \\
\hline G1 & 61 & 0 & 61 & \multirow[t]{2}{*}{$<0.001$} \\
\hline G2 & 2 & 9 & 11 & \\
\hline \multicolumn{5}{|l|}{ WHO 2000} \\
\hline 1 & 63 & 2 & 65 & \multirow[t]{3}{*}{$<0.001$} \\
\hline $1 b$ & 0 & 2 & 2 & \\
\hline 2 & 0 & 5 & 5 & \\
\hline \multicolumn{5}{|l|}{ Size } \\
\hline$\leq 2 \mathrm{~cm}$ & 63 & 5 & 68 & \multirow[t]{2}{*}{$<0.001$} \\
\hline$>2 \mathrm{~cm}$ & 0 & 4 & 4 & \\
\hline \multicolumn{5}{|c|}{ Vascular invasion } \\
\hline Yes & 0 & 4 & 4 & \multirow[t]{2}{*}{$<0.001$} \\
\hline No & 63 & 5 & 68 & \\
\hline \multicolumn{5}{|c|}{ Muscularis propria invasion } \\
\hline Yes & 0 & 4 & 4 & \multirow[t]{2}{*}{$<0.001$} \\
\hline No & 63 & 5 & 68 & \\
\hline \multicolumn{5}{|l|}{$\mathrm{Cdx} 2$} \\
\hline Positive & 1 & 1 & 2 & \multirow[t]{2}{*}{0.2} \\
\hline Negative & 58 & 8 & 66 & \\
\hline \multicolumn{5}{|l|}{ Serotonin } \\
\hline Positive & 4 & 1 & 5 & \multirow[t]{2}{*}{0.5} \\
\hline Negative & 59 & 8 & 67 & \\
\hline \multicolumn{5}{|c|}{ Pancreatic polypeptide } \\
\hline Positive & 24 & 1 & 25 & \multirow[t]{2}{*}{0.1} \\
\hline Negative & 39 & 8 & 47 & \\
\hline
\end{tabular}

icant prognostic power (table 3). The expression of $\mathrm{Cdx} 2$, serotonin or PP appeared not to be a prognostic factor in relation to metastatic potential.

The variables that had prognostic value in the univariate analysis were subsequently included in the Cox multivariate analysis. None of the variables emerged as an independent prognostic factor when either disease-specific or disease-free survival was selected as the end point.

\section{Comparison of the WHO 2010 and WHO 2000 Classifications}

A total of 65 tumours were considered benign according to the WHO 2000 criteria. Two of those patients had developed metastases later; both tumours were classified as G2 according to the WHO 2010 criteria as their proliferation index was 5\%. According to the WHO 2000 criteria, 2 tumours had been classified as having uncertain malignant potential (Ib) at initial presentation; they had later metastasised. These tumours were classified as G2 


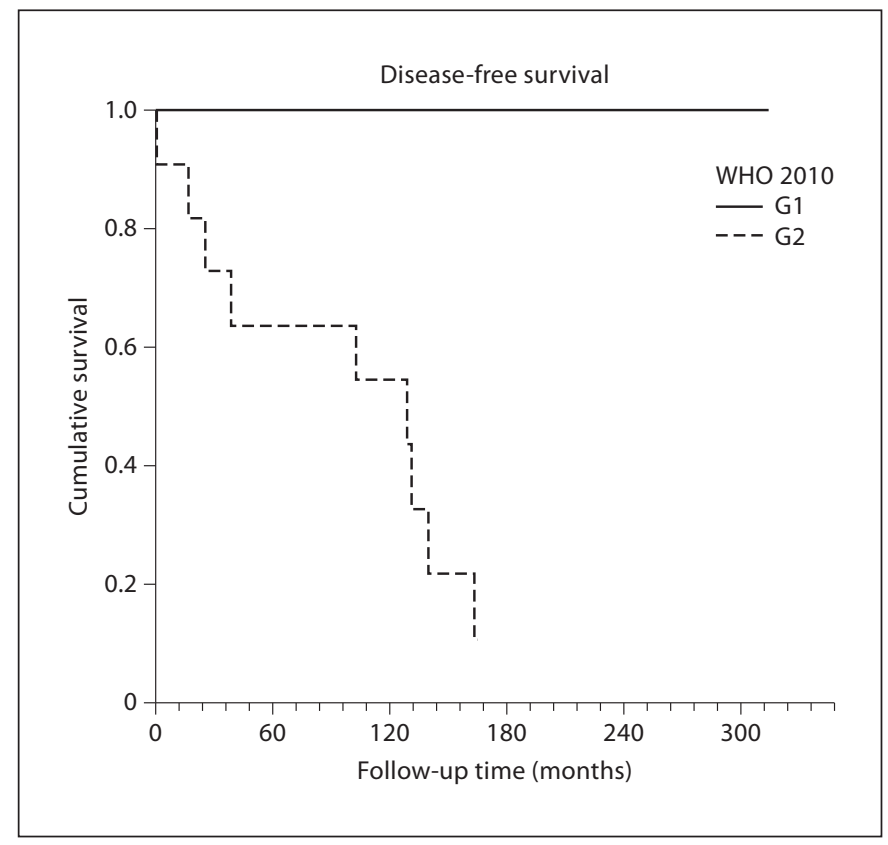

Fig. 2. Kaplan-Meier survival curves for rectal NET patients with G1 and G2 tumours; disease-free survival (occurrence of distant metastasis). With the log-rank test, the difference between the survival curves is significant $(\mathrm{p}<0.001)$.

Table 3. Log-rank test analysis of Kaplan-Meier life-tables of correlations between clinicopathological characteristics and diseasefree survival in patients with rectal NET

\begin{tabular}{llll}
\hline Variable & Patients, $\mathrm{n}$ & Test statistic & $\mathrm{p}$ value \\
\hline WHO 2010 & & & \\
$\quad$ G1 & 61 & 55.64 & $<0.001$ \\
G2 & 11 & & \\
Size & & & \\
$\quad \leq 2 \mathrm{~cm}$ & 68 & 27.77 & $<0.001$ \\
$\quad>2 \mathrm{~cm}$ & 4 & & \\
Muscularis propria invasion & & \\
$\quad$ Yes & 4 & 25.63 & $<0.001$ \\
$\quad$ No & 68 & & \\
Vascular invasion & & & \\
$\quad$ Yes & 4 & 38.81 & $<0.001$ \\
$\quad$ No & 68 & & \\
\hline
\end{tabular}

according to the WHO 2010 criteria, as their proliferation index was $5 \%$. Five metastatic tumours were considered low-grade malignant according to the WHO 2000; all 5 were G2 tumours according to the WHO 2010 classification.

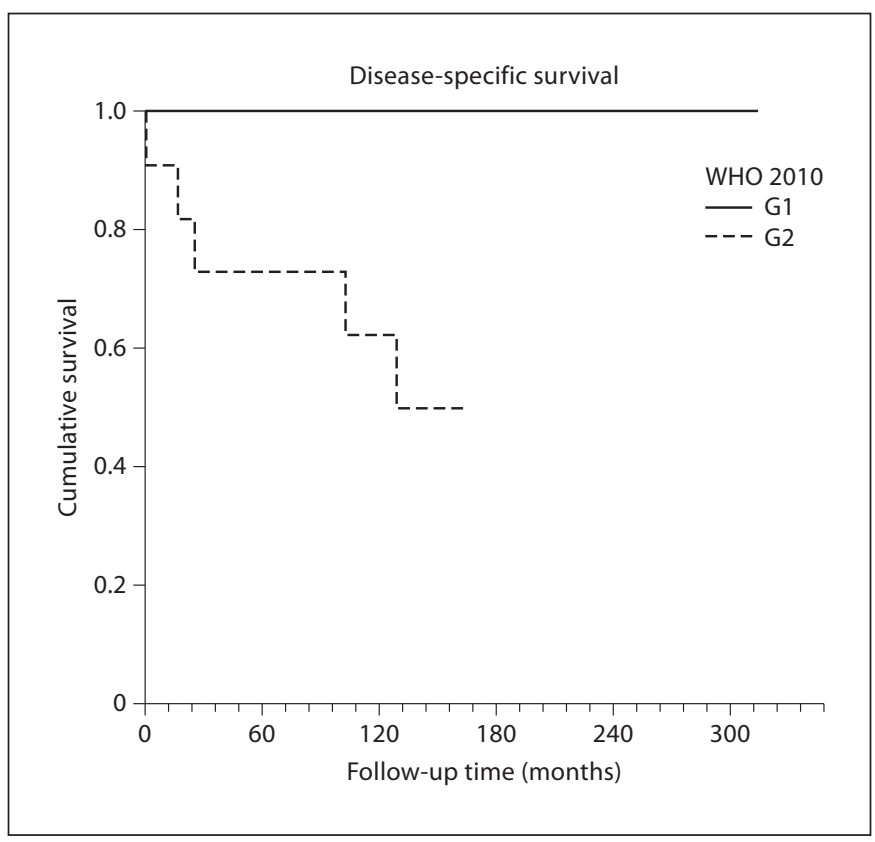

Fig. 3. Kaplan-Meier survival curves for rectal NET patients with G1 and G2 tumours; disease-specific survival (death of disease). With the log-rank test, the difference between the survival curves is significant $(\mathrm{p}<0.001)$.

Two tumours (5 $\mathrm{mm}$ and $10 \mathrm{~mm}$ in diameter) with a Ki-67 index of 5\% were G2 according to WHO 2010 and benign according to WHO 2000 (Ia). Neither tumour had recurred during follow-up (100 and 165 months).

\section{Discussion}

Several classifications of NETs have been used over the years. In the year 2000, the WHO introduced a classification and reviewed it recently, in the year 2010. To the best of our knowledge, this report is the first to compare classifications of rectal NETs. In our material of 73 NETs, the WHO 2010 was clearly superior to the WHO 2000 classification in predicting the metastatic potential of tumours and establishing a prognosis for patients.

In our material, prior to the year 2000, 71 tumours would have been classified as typical carcinoids, 1 as an atypical carcinoid and 1 as a poorly differentiated NEC (data not shown). Seven of eight metastatic rectal NETs would have been classified as typical carcinoids. According to the WHO 2000 classification, 2 tumours were considered benign but later metastasized. Both tumours were less than $2 \mathrm{~cm}$ in diameter, but had a proliferation index 
of 5\% and were thus classified as G2 under the WHO 2010 criteria. The WHO 2000 classified 2 tumours as having uncertain malignant potential. These tumours were $2 \mathrm{~cm}$ or less in diameter, but showed angioinvasion. Their proliferation index was $5 \%$ and they were thus classified as G2 according to the WHO 2010 criteria. Both tumours had metastasised later.

The WHO 2010 classification reliably identifies patients at risk for developing metastatic disease. None of the patients with G1 tumour had had metastatic disease, and all patients who had developed metastatic disease had had a primary tumour classified as G2 or G3. The WHO 2000 failed to recognise the metastatic potential of 4 tumours that had later metastasised. The ENETS recommends immunohistochemical verification of the neuroendocrine nature of the tumour with chromogranin A and synaptophysin [18]. Klöppel et al. [19] stated that NETs of the rectum are immunoreactive for synaptophysin but negative for chromogranin, while Soga [20] reported that $60.9 \%$ of rectal carcinoids were positive for chromogranin A. In this tumour series, all rectal NETs were immunoreactive for chromogranin A.

The size of the primary tumour has been associated with aggressive behaviour $[17,21,22]$. In our series, tumours $2 \mathrm{~cm}$ or less in diameter showed consistently lower metastatic potential than larger tumours $(\mathrm{p}<0.001)$. However, 4 of 8 metastasised tumours were smaller than $2 \mathrm{~cm}$. Our findings are consistent with those of Heah et al. [23] and Koura et al. [21].

Fahy et al. [24] proposed a method for risk assessment, which shows that large size, deep invasion, lymphovascular invasion and elevated mitotic rate correlated with poor prognosis. A staging system based on tumour size and invasion, lymph node metastasis, and distant metastasis showed prognostic value [25]. Immunohistochemical markers have also been proposed as prognostic indicators [26-28]. In this study, we showed that the WHO 2010 classification accurately predicts metastatic disease and the prognosis of rectal NETs. To the best of our knowledge, this is the first report to compare the prognostic significance of different classifications of rectal NETs.

The behaviour of neuroendocrine neoplasms differs by anatomic site $[22,29]$. Ileal NETs are, in general, more often malignant than NETs of the stomach or appendix. In our material, $16 \%$ of rectal NETs were G2 or G3. It is likely that malignant NETs were overrepresented in this material. The Finnish Cancer Registry revealed that 118 rectal NET patients had been diagnosed between 1980 and 2005 in our region. We believe that our material included more or less all malignant NETs of that time period and that the tumours which had been treated in small private hospitals and outpatient departments, and were thus not included in our community hospital material, were G1 neoplasms that had not metastasised.

Previously, rectal NETs had been considered small and indolent, but we now know that some of these tumours behave aggressively. Clinically, the follow-up of these patients consisted of repeated endoscopy. Here we show that G1 tumours have low metastatic potential, since all such tumours had remained local. The risk of recurrence is low, provided that the primary tumour is adequately removed. Only 3 patients with a G1 tumour had developed a local recurrence. These tumours had been removed primarily in pieces rather than by polypectomy, and the resection margins were positive. Therefore, all local recurrences had apparently been due to incomplete removal of the primary tumour.

A single follow-up endoscopy to exclude local recurrence seems sufficient in patients with a G1 tumour. Patients with a G2 tumour, on the other hand, need to be monitored much more carefully. A follow-up of up to 10 years is recommended, because metastatic lesions may occur late [30]. Repeated endoscopies alone are insufficient for monitoring these patients, but metastatic lesions should also be excluded using modern imaging techniques. When patients are chosen for intensive long-term follow-up, reliable classification of the primary tumour (including size, dissemination of disease, and proliferation activity) is essential.

The limitations of our study include its rather small number of patients, and that we collected data only from patient records without performing a detailed, uniform follow-up study of all surviving patients. This is a retrospective study, and previously, carcinoids had not always been considered malignant and therefore imaging to exclude metastases had not been a routine. Only 3 of 73 patients had undergone bowel resection, leaving lymph node status unclear in most cases. Many tumours had been removed in small pieces rather than by polypectomy, often making it difficult to identify or exclude invasion to the muscularis propria. Thus, TMN classification in our material is unreliable.

In conclusion, the WHO 2010 classification of GI NETs is useful for evaluating the malignant potential of rectal NETs. G1 NETs have low, if any, metastatic potential, whereas G2 NETs often metastasise, so such patients require intensive long-term follow-up. 


\section{Acknowledgements}

We thank Päivi Peltokangas, Tuire Koski, Elina Aspiala and Eija Heiliö for their technical support and Dr Jaana Hagström for her help with the pictures. We also thank Mia Kero for her help with the immunohistochemistry. This work was supported by Novartis Finland, the Sigrid Juselius Foundation, Finska Läkaresällskapet, Medisinska understödsföreningen Liv och Hälsa, and the Finnish Cancer Foundation.

\section{Disclosure Statement}

The authors declare that they have no conflict of interest that could appear to prejudice the impartiality of this research.

\section{References}

1 Mani S, Modlin IM, Ballantyne G, Ahlman $\mathrm{H}$, West B: Carcinoids of the rectum. J Am Coll Surg 1994;179:231-248.

$\checkmark 2$ Andrew A, Kramer B, Rawdon BB: The origin of gut and pancreatic neuroendocrine (APUD) cells - the last word? J Pathol 1998; 186:117-118.

-3 Wilson BS, Lloyd RV: Detection of chromogranin in neuroendocrine cells with a monoclonal antibody. Am J Pathol 1984;115:458468.

4 Wiedenmann B, Franke WW, Kuhn C, Moll R, Gould VE: Synaptophysin: a marker protein for neuroendocrine cells and neoplasms. Proc Natl Acad Sci USA 1986;83:3500-3504.

5 Federspiel BH, Burke AP, Sobin LH, Shekitka KM: Rectal and colonic carcinoids. A clinicopathologic study of 84 cases. Cancer 1990; 65:135-140.

6 Modlin IM, Lye KD, Kidd M: A 5-decade analysis of 13,715 carcinoid tumors. Cancer 2003;97:934-959.

7 Yao JC, Hassan M, Phan A, Dagohoy C, Leary C, Mares JE, Abdalla EK, Fleming JB, Vauthey JN, Rashid A, Evans DB: One hundred years after 'carcinoid': epidemiology of and prognostic factors for neuroendocrine tumors in 35,825 cases in the United States. J Clin Oncol 2008;26:3063-3072.

-8 Kang H, O’Connell JB, Leonardi MJ, Maggard MA, McGory ML, Ko CY: Rare tumors of the colon and rectum: a national review. Int J Colorectal Dis 2007;22:183-189.

9 Hemminki K, Li X: Incidence trends and risk factors of carcinoid tumors: a nationwide epidemiologic study from Sweden. Cancer 2001;92:2204-2210.

10 Capella C, Solcia E, Sobin LH, Arnold R: Endocrine tumours of the colon and rectum; in Hamilton SR, Aaltonen LA (eds): World Health Organization Classification of Tumours, Pathology and Genetics of Tumours of the Digestive System. IARC Press, Lyon, 2000, pp 137-139.

11 Klöppel G, Perren A, Heitz PU: The gastroenteropancreatic neuroendocrine cell system and its tumors: the WHO classification. Ann NY Acad Sci 2004;1014:13-27.
Barbareschi M, Roldo C, Zamboni G, Capelli P, Cavazza A, Macri E, Cangi MG, Chilosi M, Doglioni C: CDX-2 homeobox gene product expression in neuroendocrine tumors: its role as a marker of intestinal neuroendocrine tumors. Am J Surg Pathol 2004;28:11691176.

13 Erickson LA, Papouchado B, Dimashkieh H, Zhang S, Nakamura N, Lloyd RV: Cdx2 as a marker for neuroendocrine tumors of unknown primary sites. Endocr Pathol 2004; 15:247-252.

14 Fiocca R, Rindi G, Capella C, Grimelius L, Polak JM, Schwartz TW, Yanaihara N, Solcia E: Glucagon, glicentin, proglucagon, PYY, $\mathrm{PP}$ and proPP-icosapeptide immunoreactivities of rectal carcinoid tumors and related non-tumor cells. Regul Pept 1987;17:9-29.

15 Brenner B, Tang LH, Klimstra DS, Kelsen DP: Small-cell carcinomas of the gastrointestinal tract: a review. J Clin Oncol 2004;22: 2730-2739.

16 Bosman FT, Carneiro F, Hruban R, Theise N: WHO Classification of Tumours of the Digestive System, ed 4. International Agency for Research on Cancer (IARC), Lyon, 2010.

$\checkmark 17$ Konishi T, Watanabe T, Kishimoto J, Kotake K, Muto T, Nagawa H, Japanese Society for Cancer of the Colon and Rectum: Prognosis and risk factors of metastasis in colorectal carcinoids: results of a nationwide registry over 15 years. Gut 2007;56:863-868.

18 Ramage JK, Goretzki PE, Manfredi R, Komminoth P, Ferone D, Hyrdel R, Kaltsas G, Kelestimur F, Kvols L, Scoazec JY, Garcia MI, Caplin ME, Frascati Consensus Conference participants: Consensus guidelines for the management of patients with digestive neuroendocrine tumours: well-differentiated colon and rectum tumour/carcinoma. Neuroendocrinology 2008;87:31-39.

19 Klöppel G, Rindi G, Anlauf M, Perren A, Komminoth P: Site-specific biology and pathology of gastroenteropancreatic neuroendocrine tumors. Virchows Arch 2007; 451(suppl 1):S9-S27.

20 Soga J: Carcinoids of the rectum: an evaluation of 1,271 reported cases. Surg Today 1997;27:112-119.
21 Koura AN, Giacco GG, Curley SA, Skibber JM, Feig BW, Ellis LM: Carcinoid tumors of the rectum: effect of size, histopathology, and surgical treatment on metastasis free survival. Cancer 1997;79:1294-1298.

22 Shebani KO, Souba WW, Finkelstein DM, Stark PC, Elgadi KM, Tanabe KK, Ott MJ: Prognosis and survival in patients with gastrointestinal tract carcinoid tumors. Ann Surg 1999;229:815-821; discussion 822-823.

23 Heah SM, Eu KW, Ooi BS, Ho YH, SeowChoen F: Tumor size is irrelevant in predicting malignant potential of carcinoid tumors of the rectum. Tech Coloproctol 2001;5:7377.

24 Fahy BN, Tang LH, Klimstra D, Wong WD, Guillem JG, Paty PB, Temple LK, Shia J, Weiser MR: Carcinoid of the rectum risk stratification (CaRRS): a strategy for preoperative outcome assessment. Ann Surg Oncol 2007; 14:396-404.

-25 Landry CS, Brock G, Scoggins CR, McMasters KM, Martin RC 2nd: A proposed staging system for rectal carcinoid tumors based on an analysis of 4,701 patients. Surgery 2008; 144:460-466.

26 Wang DG, Johnston CF, Buchanan KD: Oncogene expression in gastroenteropancreatic neuroendocrine tumors: implications for pathogenesis. Cancer 1997;80:668-675.

27 Kawahara M, Kammori M, Kanauchi H, Noguchi C, Kuramoto S, Kaminishi M, Endo H, Takubo K: Immunohistochemical prognostic indicators of gastrointestinal carcinoid tumours. Eur J Surg Oncol 2002;28:140-146.

28 La Rosa S, Rigoli E, Uccella S, Chiaravalli AM, Capella C: CDX2 as a marker of intestinal EC-cells and related well-differentiated endocrine tumors. Virchows Arch 2004;445: 248-254.

29 Maggard MA, O’Connell JB, Ko CY: Updated population-based review of carcinoid tumors. Ann Surg 2004;240:117-122.

30 Kwaan MR, Goldberg JE, Bleday R: Rectal carcinoid tumors: review of results after endoscopic and surgical therapy. Arch Surg 2008;143:471-475. 